\title{
保护我国生物安全的检疫对策研究
}

范晓虹 李尉民 *

(国家质量监督检验检疫总局动植物检疫实验所，北京 100029)

摘要：本文提出广义生物安全的概念应包括人类健康、农业和环境生物 (生物多样性) 安全三个方面, 通过回顾与 其相关的国际和国内组织及法规的发展历史, 分析了生物安全管理的发展方向和存在问题,并从口岸卫生和检疫 的角度对我国的生物安全保护提出了对策。

关键词: 生物安全, 检疫, 对策

中图分类号 :S40 文献标识码 : B 文章编号 : 1005-0094(2001)04-0439-07

\section{Research on quarantine strategy for biosafety protection in China}

FAN Xiao-Hong, LI Wei-Min

Animal and Plant Quarantine Institute, State General Administration for Quality Supervision and Inspection and Quarantine , Beijing 100029

\begin{abstract}
The broad sense of the biosafety concept should be composed of human health , and safeties of agricultural and environmental organisms (biodiversities). By reviewing the phylogeny of the regulations and organizations relating to this field both worldwide and within China, and by consulting the international development trend, countermeasures aimed at the existing problems of biosafety in our country from the point of view of sanitary and quarantine are proposed.
\end{abstract}

Key words : biosafety, quarantine , strategy

生物安全的概念有狭义和广义之分。狭义的生 物安全是指防范由现代生物技术的开发和应用( 主 要指转基因技术) 所产生的负面影响即对生物多样 性、生态环境及人体健康可能构成的危险或潜在风 险（蒋志刚等，1997; 刘谦，朱金泉，2001）。广义的 生物安全包括了更广泛的内容。大致可以分为 3 个 方面 :一是指人类的健康安全 ;二是指人类赖以生存 的农业生物安全;三是指与人类生存息息相关的生 物多样性, 也就是环境生物安全。国内对生物安全 的认识很多还局限在狭义的概念上。虽然国际上对 此也还没有一个统一的认识, 但一些发达国家如澳 大利亚、新西兰、美国等，已经开始应用生物安全的 广义内涵。

\section{1 生物安全的外来威胁}

一般来说, 生物安全所受到的外来威胁主要来 自以下几个方面 :

1.1 人类和农业生物的各种外来有害生物

这类外来有害生物包括各种传染病、害虫、真 菌、细菌、线虫、病毒和杂草等。古今中外由于外来 有害生物危害人类健康和农业生物的安全，给人类 带来的灾难是十分沉痛的。公元 6 世纪下半叶, 鼠 疫 (plague) 病菌从非洲侵入中东, 进而到达欧洲, 造 成约 1 亿人死亡, 甚至导致了拜占庭帝国 ( 即东罗 马帝国)的衰亡 (张彦明, 邹世品, 1994);1845 年马 铃薯晚疫病 (Phytophthora infestans) 侵入欧洲, 造成 了历史上著名的大饥荒,夺去了数十万人的生命 (农业大词典编辑委员会，1998）；1984 年禽流感 (Avian influenza) 随国外引进的一只鹦陚传入北京， 不得不扑杀 40 万只鸡, 造成直接经济损失 1000 万 元人民币(阙保东, 1984); 1996 年, 疯牛病 (Bovine spongiform encephalopathy) 衲害英国, 直接经济损失 在 156 亿美元以上 (肖良等,1997);2001 年口蹄疫 (Foot-and-mouth disease) 传入英国，进而进入欧洲 
大陆，造成巨大损失。

\section{2 外来生物入侵}

外来生物入侵一般指非本地生物的定殖导致生 物多样性的下降甚至丧失，严重危害环境生物安全 的现象 (Bright，1998;Moore et al. ,1998) ,也有人称 之为 生物污染”。

虽然历史上有不少外来生物曾经为人类造福， 如美国种植的作物 $100 \%$ 均为外来物种，但外来生 物入侵每年给人类和环境造成的损失却是巨大的。 据 1999 年康奈尔大学公布的研究结果表明,美国由 于外来有害生物和外来生物入侵所造成的直接经济 损失每年都达 1226 亿美元（李尉民，1999）。据国 家环保总局的估算，我国由于部分外来有害生物和 外来生物入侵所造成的损失每年都在 574 亿元人民 币以上。

\section{3 外来转基因生物}

随着现代科学技术的发展, 世界上出现了越来 越多的转基因生物。转基因生物是通过现代生物重 组 DNA 技术导入外源基因的生物，因此从某种意义 上说转基因生物也是外来生物。正如核技术一样， 转基因技术存在着一定风险，既可以造福人类也可 以危害人类。一些科学家认为, 转基因生物有可能 对人类健康、农业生物和环境生物构成极大的威胁 (李尉民等 2000)。

2 国际上防范生物安全外来威胁的法规、机 构及其发展

\section{1 有关人类健康和农业生物安全的法规}

应该说生物安全问题很早就引起了人们的重 视。1 4 世纪中叶, 威尼斯当局为防止鼠疫和霍乱 (Cholera) 等威胁人类生命的外来有害生物，强制所 有外来船只连同船上人员和货物隔离 40 天检查，没 有疫病才允许进港登陆“, 检疫” ( Quarantine) 一词 即来源于此, 原意就是“四十天”（房纬廉，贾东， 1995 ）。随后，许多国家纷纷仿效，并相继制定了卫 生检疫法规, 成立了卫生检疫机构。1892 年和 1897 年一些国家联合签订了防范霍乱和鼠疫的国际卫生 公约,后来又成立了一些地区卫生组织。1948 年正 式成立了世界卫生组织(WHO) ,1951 年通过了防 范霍乱、鼠疫、天花 (Smallpox) 和黄热病 (Yellow fever) 的国际卫生条例，1969 年修订成为《国际健康 条例》。1962 年成立了卫生法典委员会, 开始规范
食品卫生，防范食品传播疾病。这些卫生检疫法规 和机构有效地阻止了许多危害人的外来有害生物的 危害, 保护了人类健康 (表 1 )。

19 世纪中后期和 20 世纪初, 由于一系列的农 业生物外来有害生物的灾害, 人们开始建立防范农 业生物的外来有害生物, 保护农业生物安全的动植 物检疫制度。1872 年法国针对根瘤蚜( Viteus vitifolii) 颁布了禁止从国外输入葡萄枝条的法令, 1886 年日本制定了有关动物检疫的法令。随后世界各国 都相继实施了各种动植物检疫的法令。1881 年一 些国家联合制定了《国际葡萄根瘤蚜公约》,1914 签 署了《国际植物病理公约》,1924 年成立了国际兽医 局,1968 年开始出版《国际动物卫生法典》。1943 年成立了联合国粮农组织（FAO）,1951 年签署了 《国际植物保护公约》。这些动植物检疫法规和机 构有效地阻止了许多危害农业生物的外来有害生物 的危害, 保护了农业生物的安全 (表 2)。

1994 年乌拉圭回合贸易谈判最终达成《实施卫 生和植物卫生措施协定》(SPS), 并成为 1995 年成 立的世界贸易组织 ( WTO) 的贸易规则, 充分肯定了 卫生检疫和动植物检疫对于防范外来有害生物危 害, 保护人体健康和农业生物安全的作用(姚文国， 1997 ; 李仲周等 2000)。

2.2 有关环境生物安全和外来生物入侵的法规

20 世纪 60 年代以后, 随着生态学研究的深入, 人们逐渐认识到环境生物安全的重要性, 各个国家 开始了环境保护的立法, 并开始设置有关机构。虽 然这些法规和机构还没有涉及外来生物入侵的概 念，但实际上为防范外来生物入侵做了充分的准备。 经过多年的努力, 1992 年 175 个国家签署了《生物 多样性公约》, 决定采取一致行动保护全世界的环 境生物, 同时要求缔约国要防止外来生物对生态环 境的威胁 (中华人民共和国濒危物种科学委员会, 中国科学院生物多样性委员会,1997)。2000 年世 界自然保护同盟制定了《防止因生物入侵而造成生 物多样性损失指南》, 建议建立生物安全机构, 防范 外来生物入侵。

在防范外来生物入侵, 保护环境生物安全方面, 美国走在世界各国的前面。1996 年美国就颁布了 《国家入侵物种法》,防范外来水生生物入侵, 保护 本地水生生物。1999 年美国总统克林顿又签署了 第 13112 号法令, 要求各联邦政府机构联合行动防 
表 1 国际上防范危害人类健康的外来有害生物的法规、机构及其发展

Table 1 Development of international regulations and organizations against foreign pest for human beings

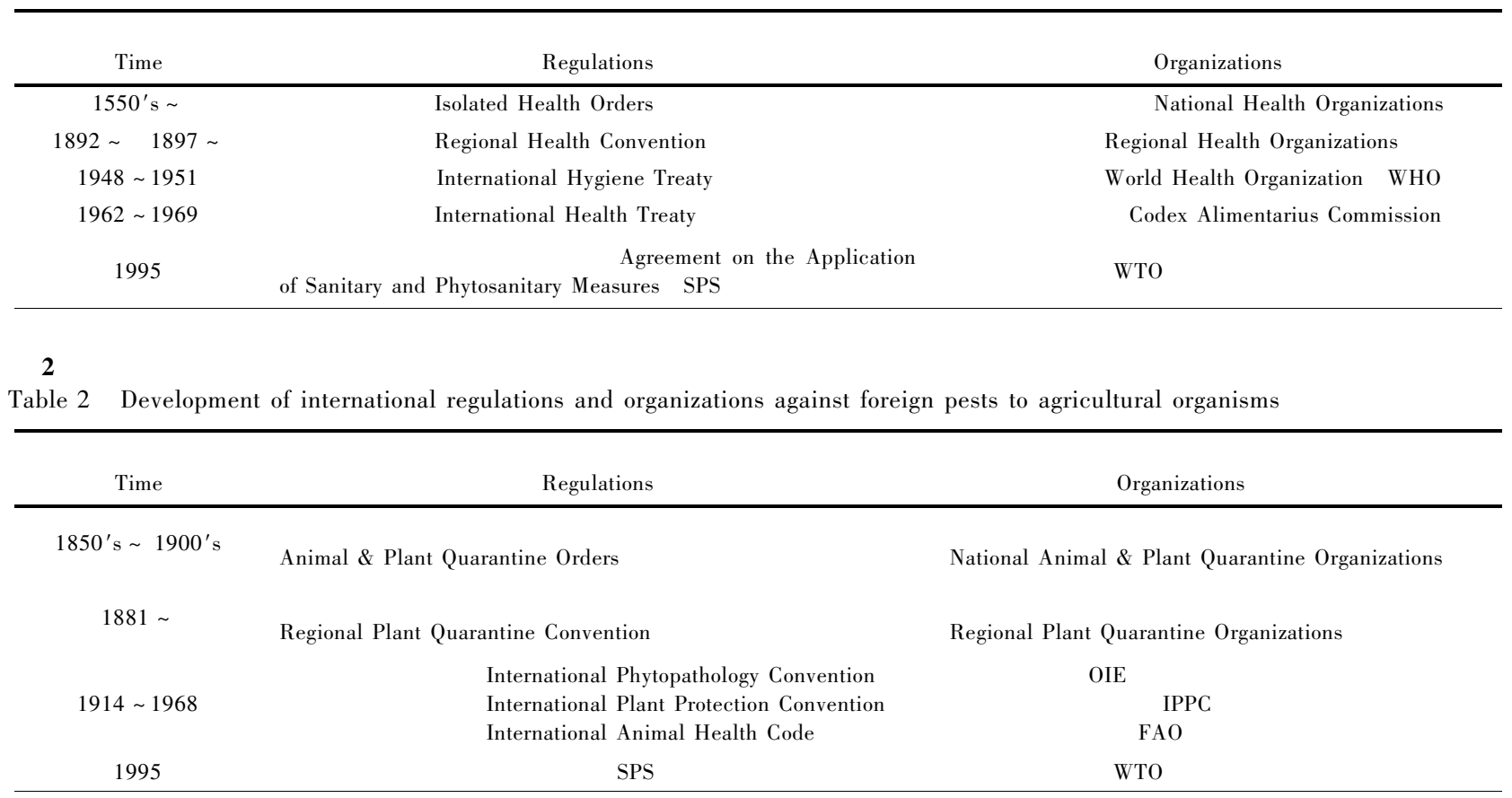

表 3 国际上防范外来生物入侵的法规、机构及其发展

Table 3 Development of international regulations and organizations against bioinvasions

\begin{tabular}{|c|c|c|}
\hline $\begin{array}{l}\text { 年 代 } \\
\text { Time }\end{array}$ & $\begin{array}{c}\text { 法 规 } \\
\text { Regulations }\end{array}$ & $\begin{array}{c}\text { 组 织 } \\
\text { Organizations }\end{array}$ \\
\hline 1996 & 美国国家入侵物种法 National Invasive Species Law & \\
\hline 1999 & $\begin{array}{l}\text { 美国第 } 13112 \text { 号法令一一入侵物种 } \\
\text { Executive Order } 13 \text { 112-Invasive Species }\end{array}$ & $\begin{array}{l}\text { 美国入侵物种委员会 } \\
\text { US Invasive Species Council }\end{array}$ \\
\hline
\end{tabular}

表 4 国际上管理外来转基因生物的法规、机构及其发展

Table 4 Development of international regulations and organizations for the management of foreign transgenic organisms

\begin{tabular}{|c|c|c|}
\hline $\begin{array}{l}\text { 年 代 } \\
\text { Time }\end{array}$ & $\begin{array}{c}\text { 法规 } \\
\text { Regulations }\end{array}$ & $\begin{array}{c}\text { 组 织 } \\
\text { Organizations }\end{array}$ \\
\hline 1980 's & $\begin{array}{l}\text { 国家转基因生物安全法规 } \\
\text { National Transgenic Organisms Safety } \\
\text { Regulation }\end{array}$ & $\begin{array}{l}\text { 国家转基因生物安全管理组织 (卫生、农业、环境保护部门) } \\
\text { National Transgenic Organisms Safety Organizations ( Human Health } \\
\text { Agriculture and Environment Protection Organizations) }\end{array}$ \\
\hline 2000 & $\begin{array}{l}\text { 卡塔赫纳生物安全议定书 } \\
\text { Cartagena Protocol on Biosafety }\end{array}$ & $\begin{array}{l}\text { 卡塔赫纳生物安全议定书 } \\
\text { Cartagena Protocol on Biosafety }\end{array}$ \\
\hline
\end{tabular}

范各种外来生物的入侵。美国的动植物检疫机构已 经开始在防范外来生物入侵方面发挥作用 ( 李尉 民 ,1999)(表 3)。

\section{3 有关转基因技术的安全法规}

20 世纪 80 年代以后,世界各国为保障现代生 物技术的健康发展，陆续建立了各自的基因工程生 物安全的管理法规和机构,这些法规和机构虽然不 是针对外来转基因生物的,但是随着转基因生物国 际贸易的增加，一些国家已经根据原有的安全管理
法规对外来转基因生物进行限制, 多数国家开始准 备对外来转基因生物立法管理, 其中有不少国家的 卫生和动植物检疫机构以及环境保护机构在实际工 作中也已经开始了对外来转基因生物进行管理。 2000 年《生物多样性公约》缔约国经过多轮谈判后, 通过了《卡塔赫纳生物安全议定书》, 决定采取切实 措施防范外来转基因生物给人类健康、农业生物和 环境生物安全所造成的威胁( 李尉民等，2000）(表 4)。 


\section{4 小结}

综上所述, 国际上防范生物安全的外来威胁, 最 初开始于防范人和农业生物的外来有害生物的威 胁，因而建立了检疫法规和机构，其目的也只是保护 人和农业生物的安全。近些年又认识到仅仅这样是 不够的，已开始着手防范外来生物入侵和外来转基 因生物对生物安全的威胁，保护的范围在逐步扩大 到环境生物的安全, 检疫法规和机构也正在满足这 一新的要求, 开始进行更新。2000 年澳大利亚农渔 林业部成立了市场准入与生物安全保护局 (Market

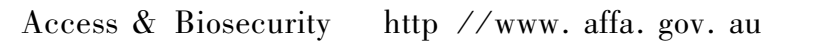
而在新西兰农林部中直接设置了生物安全保护局 ( http $: /$ www. maf. govt. nz) 负责检疫、外来生物管理 及执行实施卫生与植物卫生协定等事务, 这或许会 成为世界各国防范生物安全外来威胁的一个典范。

3 我国防范生物安全外来威胁的法规、机构 的发展及存在的问题

我国由于过去科学技术比较落后, 保护生物安 全的工作基本上是学习国外的做法。

3.1 我国防范人类和农业生物安全外来威胁的法 规

为防范人的外来有害生物的危害, 1873 年我国 在上海和厦门开展口岸卫生检疫工作。1930 年从 上海开始在部分入境口岸成立卫生检疫机构。新中 国成立后对卫生检疫非常重视，由卫生部主管，先后 制定法令并在各个入境口岸建立健全了卫生检疫机 构, 特别是 1957 年公布了《国境卫生检疫条例》, 1987 年实施了《国境卫生检疫法》,1989 年又出台 了其实施细则 (李长江,2000)。为了防范农业外来 有害生物的危害, 1927 1928 年我国陆续颁布了农 产品检验的法规，在部分入境口岸开始建立检疫机 构, 后因战争而停顿。新中国成立后, 动植物检疫受 到重视，很快就制定了动植物检疫法规，由农业部主 管陆续在各个入境口岸建立健全了动植物检疫机 构, 特别是 1982 年发布了《进出口动植物检疫条 例》。1992 年实施了《进出境动植物检疫法》,1997 年又出台了其实施条例 (夏红民,1998)。1998 年国 务院机构改革, 将原卫生部的国境卫生检疫机构、原 农业部的动植物检疫机构和原国家商品检验机构 三检合一”, 组建国家出入境检验检疫局,2001 年 又与原国家质量技术监督局合并成为国家质量监督
检验检疫总局, 执行防范人和农业生物外来有害生 物的入境检疫工作 ( 表 5 )。

我国的检验检疫机构在进境检疫中多次检出口 蹄疫、小麦矮星黑穗病菌 (Tilletia controversa) 、地中 海实蝇 (Ceratitis capitata) 等外来有害生物, 成功地 把这些人和农业生物的外来有害生物堵在了国门之 外，有效地保护了我国人民的健康和农业生物的安 全 (表 $6 \sim 8$ )。

\section{2 我国保护环境生物安全的法规}

为了保护环境生物的安全, 我国制定了一系列 有关的法律法规, 初步形成了保护环境生物安全的 法律法规体系, 主要有《环境保护法》、《海洋环境保 护法》、《森林法》、《草原法》、《渔业法》、《野生动物 保护法》、《水土保护法》等。为有效实施这些法律， 还制订了《自然保护区条例》、《野生动物保护条例》 等 20 余部行政法规。我国从 70 年代开始就设立了 环境保护机构(《中国环境保护》编委会, 2000)。虽 然没有引入外来生物入侵的概念, 但也为防范外来 生物入侵, 保护环境生物安全的工作做了准备。

\section{3 我国转基因生物管理的法规}

科技部 1993 年发布了《基因工程安全管理办 法》,从技术角度对转基因生物进行宏观管理与协 调。农业部 1996 年颁布了《农业生物基因工程安全 管理实施办法》并成立了相应的管理机构，从保护 我国农业遗传资源、农业生物工程产业和农业生产 安全的角度, 对转基因作物的实验研究、中间实验、 环境释放或商品化生产进行管理。这些和防范外来 转基因生物的威胁有一定的关系。2001 年 6 月公 布实施的《农业转基因生物安全管理条例》明确了 要对外来转基因农业生物进行管理 (表 9)。

\section{4 我国参与和履行的国际法规}

我国的检验检疫机构还参与了一些国际动植物 检疫标准、法规如《国际植物保护公约》等的制订和 修订。我国还参与并履行《生物多样性公约》、《濒 危野生动植物种国际贸易公约》等国际公约。我国 的检验检疫、环境保护和农业行政主管部门参与了 《卡塔赫纳生物安全议定书》的制定工作，我国政府 2000 年还签署了这个议定书。

3.5 我国防范生物安全外来威胁管理存在的问题

尽管我国的生物安全管理取得了一定的成绩， 但是随着贸易的发展和科技的进步, 也逐渐暴露出 一些问题。我国现行的法规和机构, 目的是保护人 
体健康和农业生物的安全, 是针对人类和农业生物 安全的外来威胁的，不是针对环境生物安全的外来 威胁的; 有关环境保护的法规和机构，也不是针对环 境生物安全的外来威胁的，外来生物入侵危害生物 多样性和生态环境的问题, 还没有引起足够的重视。 也就是说我国目前只对人和农业生物的外来有害生 物采取了防范措施, 还没有对外来生物入侵实施有 效管理。

由于这种立法和机构在管理上的漏洞,产生了 一些问题,造成了一定的经济损失。例如大米草
(Spartina anglica) 原产欧洲,1983 年福建省有关部 门从国外引入用作保滩护岸和饲料作物, 并且以行 政命令方式在霞浦县东吾洋海滩大量种植, 不料造 成巨大损失。据不完全统计, 仅 4 个乡镇沿海滩涂 由于大米草恶性繁殖, 无法养殖海产品的就达 3 万 亩,同时滩涂资源也遭破坏, 人工养殖的海带、紫菜、 牡蚛、对虾等因海水富营养化，导致水中养分降低而 连年减产，经济损失高达 1000 万元以上(杨维长， $1996)$ 。目前我国沿海海滩均有大米草的引种和自 然曼延, 损失难以估计。

表 5 中国防范人和农业生物的外来有害生物的法规、机构及其发展

Table 5 Development of Chinese regulations and organizations against foreign pests for Human Beings and Agricultural Organism
年 代
Time
法 规
Regulations
组 织
Organizations

1873

$1927 \sim 1928$

1982

1957

$1987 \sim 1989$

1995

\section{食品卫生法}

Food Hygiene Law

国家卫生法令 进出口动植物检疫条例

国境卫生检疫条例 Implementing Regulation
National Health and Quarantine Orders 农产品检验法规

Agricultural Products Inspection Regulation

Import and Export Animal and Plant Quarantine Regulation

Frontier Health and Quarantine Regulation

国境卫生检疫法及其实施细则 Frontier Health and Quarantine Law and the Specific Rules for Enforcing 进出境动植物检疫法及其实施条例

Import and Export Animal and Plant Quarantine Law and It's

1998

2001
上海地方口岸卫生检疫机构

Shanghai Local Border Health Inspection Organizations 地方口岸检疫机构

Local Border Quarantine Organizations

国家动植物检疫机构 (农业部) National Animal and Plant Quarantine Organizations (Ministry of Agriculture ,MOA)

\section{国境卫生检疫机构 ( 卫生部)}

National Border Health Inspection Organizations

\section{国境卫生检疫机构 ( 卫生部)}

National Border Health Inspection Organizations 国家动植物检疫机构 (MOA)

National Animal and Plant Quarantine Organizations

\section{国境卫生检疫机构 (卫生部)}

National Border Health Inspection Organizations

国家出入境检验检疫局 State Administration for Entry-Exit Inspection and Quarantine (CIQ SA)

国家质量监督检验检疫总局

State General Administration for Quality Supervision and Inspection and Quarantine ( AQSIQ)

表 61998 年入境货物动植物检疫业务统计表

Table 6 Statistics of entry animal and plant quarantine on cargoes in 1998

\begin{tabular}{|c|c|c|c|c|c|c|c|}
\hline \multirow[b]{2}{*}{$\begin{array}{l}\text { 项目分类 } \\
\text { Items }\end{array}$} & \multirow[b]{2}{*}{$\begin{array}{l}\text { 批次 } \\
\text { Batch }\end{array}$} & \multicolumn{6}{|c|}{ 截获疫情 Pest interception } \\
\hline & & $\begin{array}{l}\text { 一类有害 } \\
\text { 生物批次 } \\
\text { Pests in list } \\
\text { A ( batch) }\end{array}$ & $\begin{array}{c}\text { 一类有害 } \\
\text { 生物类种 } \\
\text { Numbers of species } \\
\text { in list A }\end{array}$ & $\begin{array}{l}\text { 二类有害 } \\
\text { 生物批次 } \\
\text { Pests in list } \\
\text { B ( batch) }\end{array}$ & $\begin{array}{c}\text { 二类有害 } \\
\text { 生物类种 } \\
\text { Numbers of } \\
\text { species in list A }\end{array}$ & $\begin{array}{c}\text { 其他有害 } \\
\text { 生物批次 } \\
\text { Other pests } \\
\text { ( batch) }\end{array}$ & $\begin{array}{l}\text { 其他有害 } \\
\text { 生物类种 } \\
\text { Numbers of } \\
\text { other pests }\end{array}$ \\
\hline $\begin{array}{c}\text { 动物 } \\
\text { Animals }\end{array}$ & 9962 & 88 & 4 & 411 & 26 & 209 & 22 \\
\hline $\begin{array}{c}\text { 动物产品 } \\
\text { Animal products }\end{array}$ & 137477 & 0 & 0 & 187 & 20 & 86 & 11 \\
\hline $\begin{array}{l}\text { 植物 } \\
\text { Plant }\end{array}$ & 4843 & 4 & 3 & 2 & 2 & 74 & 34 \\
\hline $\begin{array}{c}\text { 植物产品 } \\
\text { Plant products }\end{array}$ & 1138135 & 132 & 15 & 1467 & 98 & 1183 & 221 \\
\hline 小计 Total & & 224 & & 2067 & & 1552 & \\
\hline
\end{tabular}


表 71998 年入境运输工具动植物检疫业务统计表

Table 7 Statistics of entry animal and plant quarantine on conveyance in 1998

\begin{tabular}{|c|c|c|c|c|c|c|c|}
\hline \multirow[b]{2}{*}{$\begin{array}{l}\text { 项目分类 } \\
\text { Items }\end{array}$} & \multirow[b]{2}{*}{$\begin{array}{l}\text { 批次 } \\
\text { Batch }\end{array}$} & \multicolumn{6}{|c|}{ 截获疫情 Pest interception } \\
\hline & & $\begin{array}{l}\text { 一类有害 } \\
\text { 生物批次 } \\
\text { Pests in list } \\
\text { A ( batch) }\end{array}$ & $\begin{array}{c}\text { 一类有害 } \\
\text { 生物类种 } \\
\text { Numbers of species } \\
\text { in list A }\end{array}$ & $\begin{array}{c}\text { 二类有害 } \\
\text { 生物批次 } \\
\text { Pests in list } \\
\text { B ( batch) }\end{array}$ & $\begin{array}{c}\text { 二类有害 } \\
\text { 生物类种 } \\
\text { Numbers of } \\
\text { species in list A }\end{array}$ & $\begin{array}{c}\text { 其他有害 } \\
\text { 生物批次 } \\
\text { Other pests } \\
\text { ( batch) }\end{array}$ & $\begin{array}{l}\text { 其他有害 } \\
\text { 生物类种 } \\
\text { Numbers of } \\
\text { other pests }\end{array}$ \\
\hline $\begin{array}{l}\text { 火车 } \\
\text { Trains }\end{array}$ & 24206 & & & & & & \\
\hline $\begin{array}{l}\text { 船 } \\
\text { Ships }\end{array}$ & 139603 & 52 & 19 & 342 & 24 & 511 & 56 \\
\hline $\begin{array}{c}\text { 飞机 } \\
\text { Planes }\end{array}$ & 32343 & & & & & & \\
\hline $\begin{array}{c}\text { 集装箱 } \\
\text { Containers }\end{array}$ & 2802602 & & & 2 & 2 & 23 & 7 \\
\hline $\begin{array}{c}\text { 邮检 } \\
\text { Mails inspection }\end{array}$ & 4231 & & & & & & \\
\hline $\begin{array}{l}\text { 旅检 Passengers } \\
\text { inspection }\end{array}$ & $\begin{array}{c}109871 \\
\text { ( 航班 Flights) }\end{array}$ & 3 & 2 & 604 & 54 & 50 & 17 \\
\hline $\begin{array}{l}\text { 小计 } \\
\text { Total }\end{array}$ & & 55 & & 948 & & 584 & \\
\hline
\end{tabular}

二类、二类有害生物是指中华人民共和国农业部公布的进境动物一、二类传染病、寄生虫病名录和植物检疫色险性病、虫、杂草名录中规定的有 害生物;其他有害生物指名录之外的有害生物

Pests in list A and B means the pests in the lists of Class A and Class B infectious or parasitic diseases of animals, and diseases, pests or weeds dangerous to plants announced by the Ministry of Agriculture of the People's Republic of China, other pests mean the pests other than the pests in above mentioned lists.

表 81998 年出入境卫生检疫业务统计表

Table 8 Statistics of frontier health and quarantine in 1998

\begin{tabular}{lcc} 
项目 Item & 数量 Quantities & 问题 Problems \\
交通工具 & 465862 (艘) & 除鼠 Removing rats 13883 (只) \\
Vehicles & 135126 (架) & 除虫 Removing insects 11370 (次) \\
& 72047 (列) & 消毒 Sterilization 368085 (次) \\
人员 Persons & 12016552 (辆) & 体检发现问题 \\
食品 Food stuff & 70942456 (人次) & $\begin{array}{c}\text { Problems found in health examinations } 53772 \text { (人次) } \\
\text { 预防接种 Inoculation } 873730 \text { (人次) }\end{array}$ \\
集装箱 Containers & 2234989 (吨 ton) & 609776 (吨 ton) \\
\hline
\end{tabular}

表 9 中国管理外来转基因生物的法规、机构及其发展

Table 9 Development of Chinese regulations and organizations for the management of foreign transgenic organisms

年 代 Time

1996

2001
法 规 Regulations

农业生物基因工程安全管理实施办法

Implementing Regulation on Safety Administration for Genetic Engineering of Agricultural Organisms

农业转基因生物安全管理条例 Regulation on Safety Administration for Agricultural Transgenic Organisms
组 织 Organizations

基因工程安全管理办公室 ( $\mathrm{MOA})$

Office of Safety Administration for Genetic Engineering

MOA , AQSIQ
再如水葫芦 (Eichhornia crassipes) 大约在 20 世 纪 30 年代作为畜禽饲料引入我国,50 70 年代作 为观赏和净化水质植物推广种植, 后逃逸为野生。 由于其无性繁殖速度极快，往往形成单一的优势种，
严重降低当地的生物多样性。以云南的滇池为例， $1000 \mathrm{hm}^{2}$ 的水面近 $100 \%$ 被水葫芦覆盖, 使滇池内 的很多水生生物已处于灭绝的边缘。资料记载, 20 世纪 60 年代以前滇池主要有水生植物 16 种, 水生 
动物 68 种，但到 80 年代大部分水生植物相继消亡， 水生动物仅存 30 余种 (丁建清等,1999)。

虽然我国已经颁布了《农业转基因生物安全管 理条例》,对于外来转基因农业生物有了管理规定， 但对外来非农业转基因生物还没有管理的法规。另 外, 该条例的实施还需要制定更具体的可操作的管 理办法。

\section{4 对策及建议}

已有全国人大代表向全国人大常委会提出,要 尽快制定我国的生物安全法。实际上还可以在现有 法规的基础上作一些修订，进一步完善法规体系。 例如, 修订现有的动植物检疫和环境保护法规, 加强 出入境检疫工作, 把检疫的目的由保护人体健康和 农业生物扩大到保护环境生物，克服针对性检疫的 弊端，由国家入境检疫机构统一管理，不仅对人和农 业生物外来有害生物进行严格检疫，也不仅仅保护 人体健康和农业安全和卫生安全, 要对所有入境外 来生物进行严格的检疫,防止外来生物入侵和外来 转基因生物对生物安全的威胁。要贯彻和实施好 《农业转基因生物安全管理条例》,并制定出切实可 行的入境转基因生物检验检疫管理办法, 开展对入 境转基因生物的监管工作。实际上我国的入境检疫 机构已经为转基因生物检测和环境生物安全评估做 好了技术上的准备。我国目前入境检疫机构是独立 于卫生、农业和环境保护部门之外的部级单位, 这也 为其职责的扩大做好了组织上的准备。

在修订立法和扩大机构职责之前, 我国的检疫 机构应在实际工作中逐步扩展自己的管理范围，可 以依据《进出境动植物检疫法》中其他有害生物” 的解释“: 动物传染病、寄生虫病和植物危险性病、 虫、杂草以外的各种为害动植物的生物有机体、病原 微生物，以及软体类、啮齿类、螨类、多足虫类动物和 危险性病虫的中间寄主、媒介生物等”，将外来生物 入侵视为 其他有害生物” 的范畴, 对其入境实施严 格的控制，防范危害我国生物安全的各种外来威胁。 例如在引进象上述水葫芦和大米草这样的外来生物 前应进行农业、林业、环境等多学科参与的全面的风 险分析，在得出风险可以控制的结论的前提下，才能 允许局部引进, 并进行一定时期的跟踪监测,一旦出
现问题可以快速及时地控制或根治;否则均不得入 境。

\section{参考文献}

丁建清, 王韧, 付卫东, 2000. 外来有害植物对我国生物多样 性的影响及其治理现状与对策. 见: 许智宏 (主编), 面 向二十一世纪的中国生物多样性保护一一第三届全国 生物多样性保护与持续利用研讨会论文集. 北京: 中国 林业出版社, $297 \sim 306$

房纬廉, 贾东, 1995. 进出境动植物检疫的理论和实务. 北 京: 中国农业出版社

阙保东, 1984. 实用动物检疫技术. 北京: 中国农业出版社 蒋志刚, 马克平, 韩兴国, 1997. 保护生物学. 杭州: 浙江科学 技术出版社

李长江, 2000. 中国出入境检验检疫指南. 北京: 中国检察出 版社

李尉民, 岳宁, 曹苦, 2000。《卡塔赫纳生物安全议定书》及其 对转基因农产品国际贸易和生物技术发展的影响与对 策. 生物技术通报, (5) : 7 10

李尉民, 岳宁, 夏红民, 2000. 转基因生物及其产品的风险与 管理. 生物技术通报, (4): $41 \sim 44$

李尉民, 1999. 国际出入境检疫发展趋势及中国应采取的对 策. 中国检验检疫, (7) :5 6

李仲周, 易小准, 何宁, 2000. 乌拉圭回合多边贸易谈判结果 法律文本. 北京: 法律出版社

刘谦, 朱金泉, 2001. 生物安全. 北京: 科学出版社

农业大词典编辑委员会, 1998. 农业大词典. 北京: 中国农业 出版社, 6

夏红民, 1998. 中国的进出境动植物检疫. 北京: 中国农业出 版社

肖良, 李通瑞, 段小红, 1997. 疯牛病给英国带来的灾难. 世 界农业, (3) : 42 43

杨维长, 1996. 进出境动植物检疫与国际贸易. 天津: 天津 人民出版社

姚文国, 1997. 国际多边贸易规则与中国动植物检疫. 北京: 法律出版社

张彦明, 邹世品, 1994. 人兽共患病. 西安: 西北大学出版社 中国环境保护编委会, 2000. 中国环境保护. 北京: 中国环境 科学出版社

中华人民共和国濒危物种科学委员会, 中国科学院生物多样 性委员会, 1997. 生物多样性公约指南. 北京: 科学出版 社

www. affa. gov. au Department of Agriculture Fisheries and Forestry, Australia 澳大利亚农渔林业部

www. maf. govt. nz Ministry of Agriculture and Forestry, New Zealand 新西兰农林部

Chris Bright, 1998. Life out of Bounds: Bioinvasion in a Borderless World. USA, Paperback

Janet M M, Nancy L, Nancy B and Victoria L, 1998. Bio-invasions: Breaching Natural Barrier. A Washington Sea Grant Program Publication, University of Washington, Seattle 